Bangladesh J Med Microbiol 2018; 12 (1): 1-3

Bangladesh Society of Medical Microbiologists

\title{
Editorial
}

\section{Mysteries of Melioidosis: Unearthing the Enigma}

\author{
Md Shariful Alam Jilani ${ }^{1}$, Saika Farook ${ }^{2}$ \\ ${ }^{1}$ Department of Microbiology, Ibrahim Medical College, Dhaka. \\ ${ }^{2}$ Department of Microbiology, BIRDEM General Hospital, Dhaka.
}

One of the most fascinating aspects of medical microbiology is the periodic discovery of emerging and reemerging organisms. In recent years, the SARS-CoV-2, Human Immunodeficiency Virus (HIV), Nipah virus, Ebola virus, Legionella species, Helicobacter pylori and other new pathogens have been discovered. Although Burkholderia pseudomallei, the causative agent of melioidosis has been described almost a century ago and considerable progress in terms of diagnosis and treatment was achieved, $B$. pseudomallei is still "the unbeatable foe", for several reasons like under-recognition, high case-fatality rate, unacceptable relapse rate and a "time-bomb" effect for sero-positive individuals. ${ }^{1}$ There is a growing body of evidence that, once considered an obscurity, melioidosis is now recognised as an emerging disease of global significance. It represents an excellent example of an emerging disease in two respects: it is being reported increasingly in many countries; and it is being recognised for the first time in countries where it has not previously been described. This frequently fatal infection of man and numerous other animal species is a facultative intracellular Gram-negative ß-proteobacterium. The world wide distribution of this organism is still unknown and our understanding of the environmental factors determining the presence of $B$. pseudomalle $i$ is rudimentary. It is believed that the organism is a ubiquitous soil and water dwelling saprophyte of tropical and subtropical regions worldwide; a relationship in the high incidence of disease among people sharing a close association with the environment. Just like Mycobacterium tuberculosis, the organism can remain latent for decades before the onset of clinical signs and symptoms. ${ }^{2}$ Infection follows aspiration of contaminated water, inoculation of bacteria through traumatic skin breaches or inhalation of contaminated

Correspondence:

Md Shariful Alam Jilani

Department of Microbiology

Ibrahim Medical College, Dhaka. dusts and aerosols. ${ }^{3,4}$ There is a substantial number of factors that have driven melioidosis research, most importantly: increasing awareness and discovery of B. pseudomallei in areas outside the previously recognised regions of endemicity, the recent surge in disease associated with survivors of the December 2004 tsunami in Indonesia and the accelaration of bioterrorism research in light of the Bacillus anthacis mailing in United States of America which has raised public awareness of health security, and in particular the threat of bioterrorism. ${ }^{3}$

The pioneering work of Indian bacteriologist C. S. Krishnaswami and British pathologist Alfred Whitmore first identified the organism Burkholderia pseudomallei, among Burmese morphine addicts in 1911.5,6 Since then, it took a century to determine its source in the environment of Indian sub-continent. The organism was recovered for the first time in 2011 from soil of Gazipur district of Bangladesh. ${ }^{7}$ However, the first case of melioidosis from Bangladesh was reported in 1964 in a 29 year old British sailor who was travelling through Bangladesh and stayed in Chittagong for 3 months. ${ }^{8}$ Since then, melioidosis has been sporadically detected in Bangladesh over last several decades. But first melioidosis case in a native Bangladeshi child was diagnosed in 1988. ${ }^{9}$ Subsequently, five more cases were detected in U.K among Bangladeshi immigrants from Sylhet region from 1991 to $1999 .{ }^{10,11,12}$ Later on, at least 35 culture-confirmed melioidosis cases were detected among the diabetic patients in Bangladesh and most of these cases were diagnosed at Ibrahim Medical College and BIRDEM Hospital in Dhaka from 2001 to 2016.13 Analysis of the reported cases strongly indicate that the disease is potentially endemic in at least ten districts of Bangladesh particularly in north eastern regions (Gazipur, Mymensingh, Sylhet) of the country. ${ }^{7}$ So far, 51 culture positive melioidosis cases have been diagnosed in Bangladesh. ${ }^{14}$

Many challenges exist for the control and prevention of melioidosis. At present, cellular and molecular 
mechanisms associated with these diverse clinical manifestations are not fully understood. Vaccine development and better therapeutics are necessary to prevent and treat melioidosis. However, knowledge of the relationship between hosts and pathogen is still limited. This has hindered improved vaccine and therapeutic developments, which require a full understanding of genomics and bacterial pathogenesis. After the first genome of B. pseudomallei K96243 was released in 2004, subsequent studies capitalized upon this foundation, which lead to enhanced genetic and genomic analyses that have facilitated a better understanding of this organism. As additional genomic sequences have been generated, striking differences have been observed. For example, two mutually exclusive gene cassettes, termed "BTFC and YLF", have been described that are dissimilar in their geographical distribution ${ }^{15}$ as well as in terms of pathogenicity. A study conducted in Bangladesh showed all B. pseudomallei isolated in Bangladesh posses YLF gene, which confirms their Asian origin. As YLF strains are more virulent than BTFC strains, so people in this region are at higher risk of severe form of infection. Multi-locus sequence typing (MLST) has revealed that a number of novel sequence types of B. pseudomallei exist in Bangladesh environment and these same sequence types are present in soil as well as in melioidosis patients from same geographic area. ${ }^{7}$

It is noticed that this killer disease has been raising its ugly head in recent times and it is high time the microbiologists engaged in tackling this disease come together to face the challenge. Recently, the global environmental distribution of $B$. pseudomallei and the world-wide incidence and mortality of melioidosis was estimated using a modeling approach. It was predicted that 165,000 melioidosis cases occur per year worldwide, in which 89,000 die. ${ }^{16}$ Unfortunately, this infectious disease has still remained in the shadows for far too long. It is still considered a rare and esoteric disease in many countries, and consequently it does not feature highly on the syllabus of Medical Colleges or even postgraduate courses. If clinicians are not aware of the disease, they will be unable to make the diagnosis. Perhaps the best example of this problem is Myanmar, where melioidosis was first discovered and where, in 1913, Krisnaswami reported that approximately $5 \%$ of the autopsies he performed in Rangoon were cases of the disease. ${ }^{5,6}$ Yet in 1990s, few Burmese doctors had ever heard of melioidosis. ${ }^{17}$ The most striking reason for this unawareness is that, melioidosis is still considered as one of the most neglected tropical diseases (NTDs), so much so that it is not even included in the WHO list of NTDs. Yet the modeling suggests that it kills more people worldwide every year than diseases that are much known, such as leptospirosis and dengue.
Whilst specific details regarding the immunopathogenesis of melioidosis are accumulating, comparatively little is known concerning the organism's niche and reservoir of infection. Burkholderia are key microbial consituents of the rhizosphere and have significant roles including the provision of nutrients to the growing plant nodule, fixation of atmospheric nitrogen, inhibition of plant pathogens including fungi, and degradatrion of complex compounds. They are versatile and inhabit ecological niches as varied as rice paddy water, and water holes and sea water. This versatility has led to use of a number of Burkholderia species, for biocontrol, bioremediation, and plant growth promotion. The introduction of a biocontrol strain with the planting material reesults in the colonization of the rhizosphere and the suppression of the pathogenic competing bacteria and fungi with proven economic benefits. Other Burkholderia strains have been widely used for the bioremediation of soils and agricultural environments due to their ability to degrade complex hydrocarbons and herbicides. Such information not only has the potential to expose new therapeutic avenue, bio-active compounds and mechanisms of bioremediation ${ }^{18}$, but also to predict regions of hyperendemicity in which the disease is frequently misdiagnosed. ${ }^{19}$ The identification of such high risk areas may aid in advising traditional inhabitants of high risk areas in which bathing, washing and playing should be avoided.

In recent unpublished analyses, it has been found that when compared to existing genomic sequences, new B. pseudomallei genome sequences can contain as much as $500 \mathrm{~kb}$ of additional genomic material in the form of blocks of novel DNA known as genomic islands. It is hypothesized that the primary differences among $B$. pseudomallei genomes are horizontal gene transfer events from diverse bacterial or phage origins. Horizontal gene transfer involves the incorporation of genetic elements, perhaps directly into the genome where they form genomic islands. ${ }^{20}$ Currently, very little is known about the adaptability or fitness of $B$. pseudomallei. It seems likely that the genes contained in genomic islands may generate unique phenotypes and affect bacterial fitness, such as the interaction of bacterial cells with their surrounding environment. Fitness phenotypes could range from the ability to survive under extreme environmental conditions to the ability to defeat host immune system defenses.

This bacterium still has many secrets left to be revealed. So, currently we need to perform whole genome sequencing of both clinical and environmental isolates of B. pseudomallei hailing from a particular region of the country and present a comparative analysis to identify 
essential genes involved in their pathogenicity, adaptability and drug resistance mechanisms. Such study will also help us to understand the phylogenetic relationship among strains persisting in Bangladesh with foreign strains. Deep analysis of the complete genome will be helpful for us in understanding the evolution of the bacterium and its adaptation to the environment, such as high temperatures and antibiotics.

\section{References}

1. Leelarasamee A. Burkholderia pseudomallei: the unbeatable foe?. Southeast Asian Journal of Tropical Medicine \& Public Health 1998 Jun 14;29 (2):410-5.

2. Ngauy V, Lemeshev Y, Sadkowski L, Crawford G. Cutaneous melioidosis in a man who was taken as a prisoner of war by the Japanese during World War II. Journal of clinical microbiology 2005 Feb 1; 43(2):970-2.

3. Chierakul W, Winothai W, Wattanawaitunechai C, Wuthiekanun V, Rugtaengan T, Rattanalertnavee J, Jitpratoom P, Chaowagul W, Singhasivanon P, White NJ, Day NP. Melioidosis in 6 tsunami survivors in southern Thailand. Clinical infectious diseases 2005 Oct 1;41(7):982-90.

4. Wang CY, Yap BH, Delilkan AE. Melioidosis pneumonia and blast injury. Chest 1993 Jun 1; 103(6):1897-9.

5. Whitmore A. An account of a glanders-like disease occurring in Rangoon. Epidemiology \& Infection 1913 Apr;13(1):1-34.

6. Whitmore AKCS and Krishnaswami CS. A hitherto undescribed infective disease in Rangoon. The Indian Medical Gazette 1912;47(7): p.262.

7. Jilani MS, Robayet JA, Mohiuddin M, Hasan MR, Ahsan CR, Haq JA. Burkholderia pseudomallei: its detection in soil and seroprevalence in Bangladesh. PLoS neglected tropical diseases 2016 Jan 15; 10(1):e0004301.

8. Maegraith BG, Leithead CS. Melioidosis: A Case-Report. Lancet 1964;862-3.

9. Struelens MJ, Mondol G, Bennish M, Dance DA. Melioidosis in Bangladesh: a case report. Transactions of the Royal Society of Tropical Medicine and Hygiene 1988 Sep 1;82(5):777-8.

10. Dance DA, Smith MD, Aucken HM, Pitt TL. Imported melioidosis in England and Wales. The lancet 1999 Jan 16;353(9148):208.
11. Hoque SN, Minassian M, Clipstone S, Lloyd-Owen SJ, Sheridan E, Lessing MP. Melioidosis presenting as septic arthritis in Bengali men in east London. Rheumatology 1999 Oct 1;38(10):1029-31.

12. Kibbler CC, Roberts CM, Ridgway GL, Spiro SG. Melioidosis in a patient from Bangladesh. Postgraduate medical journal 1991 Aug 1;67(790):764-6.

13. Barai L, Jilani MS, Haq JA. Melioidosis case reports and review of cases recorded among Bangladeshi population from 1988-2014. Ibrahim Medical College Journal 2014;8(1):25-31.

14. Chowdhury FR, Jilani M, Alam S, Barai L, Rahman T, Saha MR, Amin M, Fatema K, Islam KM, Faiz MA, Dunachie SJ. Melioidosis in Bangladesh: a clinical and epidemiological analysis of culture-confirmed cases. Tropical Medicine and Infectious Disease 2018 Jun;3(2):40.

15. Tuanyok A, Auerbach RK, Brettin TS, Bruce DC, Munk AC, Detter JC, Pearson T, Hornstra H, Sermswan RW, Wuthiekanun V, Peacock SJ. A horizontal gene transfer event defines two distinct groups within Burkholderia pseudomallei that have dissimilar geographic distributions. Journal of bacteriology 2007 Dec 15;189(24):9044-9.

16. Limmathurotsakul D, Golding N, Dance DA, Messina JP, Pigott DM, Moyes CL, Rolim DB, Bertherat E, Day NP, Peacock SJ, Hay SI. Predicted global distribution of Burkholderia pseudomallei and burden of melioidosis. Nature microbiology 2016 Jan;1(1):15008.

17. Aung MK, Mar TT. Re-emergence of melioidosis in Myanmar. Transactions of the Royal Society of Tropical Medicine and Hygiene 2008 Dec 1;102 (Supplement_1):S10-1.

18. Cain AS. Property Rights in Human Biological Materials: Studies in Species Reproduction and Biomedical Technology. Ariz. J. Int'l \& Comp. L 2000;17:449.

19. Warner JM, Pelowa DB, Currie BJ, Hirst RG. Melioidosis in a rural community of western province, papua new guinea. Transactions of the Royal Society of Tropical Medicine and Hygiene 2007 Aug 1; 101(8):809-13.

20. Hacker J, Carniel E. Ecological fitness, genomic islands and bacterial pathogenicity. EMBO reports 2001 May 1;2(5):376-81. 